B. E. (1951) : Am. J. Clin. Path. 21 ; $475 . \quad$ 3) Richman, I. M., Gelfand, M., and Hill, J. M. (1947) : Arch. Path. 44 ; 92.4 4) Rosbash, D. O. and Leavitt, D. (1952) : Am. J. Clin. Path. 22 ; $914 . \quad 5)$ Hahn, F. L. and Reygadas, F. (1951): Science 114 ; $462 . \quad 6)$ Sreebny, L. and Nikiforuk, G. (1951) : Seience 114;560. 7) Brain, E. B. and Eastoe, J. E. (1962) : Brit. Dent. J. 112 ; $277 . \quad 8$ ) Wandelt, S. (1959); De üt. Ztschrt $17 ; 1255 . \quad 9)$ Greep, R. O., Fisher, C. J. and Morse, A. (1947) : Science $105 ; 666$. 10) Morse, A. and Greep, R. D. (1947) : Anat. Rec. 99 ; $379 . \quad$ 11) Greep, R. D., Fisher, C. J. and Morse, A. (1948) : J. Am. Dent. Ass. 36 ; 427 . 12) Schajowicz, F. and Cabrini, R. L. (1956) : Stain Technol. 31 ; 129 . 13) Sugimoto A. et al (1957) : Tr. Soc. Path. Jap. 46 ; 137 . 14) Taft, E. B. (1951) : Stain Technol. 26 ; 205.115$)$ Hotchkiss, R. D. (1948) : Studies from the Rockfeller Inst. Med. Res. 136 ; 207.1 16) Flax, M. H. and Caulfield, J. B. (1962) : Arch. Path. 74 ; 387. 17) Houck, C. E. and Dempsy E. W. (1954): Stain Technol. 29 ; 207.18$)$ Newman, S. B., Borisko, E. and Swerdlow, M. (1949); Science $110 ; 66 . \quad 19)$ Runge, J. Vernier, R. L. and Hartmann, J. F. (1958) : J. Biophy. Biol. Cytol. 4; 327.20 ) Cameron, G. R. and Scholor, G. (1930) : J. path. Bact! 33 ; $929 . \quad 21)$ Lorch, I. J. (1948) : Quat. J. Micro. Sci. 88 ; 367.22$)$ Schajowicz, F. and Cabrini, R. L. (1955) : J. Histohem. Cytochem. 3; 122. 23) Trott, J. R. (1961) : J. Histochem. Cytochem. 9;699. 24) Balogh, Jr. K. (1962) : J. Histochem. Cytochem. 10; 232.25$)$ Cook, S. F. and Ezra-Cohon, H. E. (1962) : J. Histochem. Cytochem. $10 ; 560$.

\title{
Discussion
}

Dr. H. Takamatsu

I should like to add the results of our previous studies. I and Dr. Akahoshi have previously reported the method for decalcification which uses disodium salt and tetrasodium salt of EDTA. The mixture of equal volume of them shows about neutral $\mathrm{pH}$. This mixture can be used for decalcification.

Dr. Fujita

How did you remove metacrylate from tissue sections, which have been previously embedded in methacrylate, to perform light microscopic stainings ?

Dr. Yagi

Acetone, Xylene and toluene are said to give good results in removing embedding materials such as methacrylate. I have tested the effectiveness of them and found that acetone is most effective for $4 \sim 6 \mu$ sections. Xylene and toluene are much less effective.

\section{Histochemical Demonstration of Various Dehydrogenases in Developing Teeth.}

\author{
Tsuneo Mizushima \\ Department of Oral Surgery (Prof. K. Kawakatsu) Osaka University Dental \\ School, Joan-cho, Kita-ku, Osaka
}

\section{Introduction}

Histochemical studies of developing teeth have been made in detail especially for the distribution of hydrolytic enzymes. ${ }^{1-7)}$ It is reported that alkaline phosphatase $e^{1,5)}$ proved to be related with a matrix formation, mineralization and 
differentiation of immature cells. But, a few communications have been made concerning the localization of various dehydrogenases in developing teeth.

The present paper deals with a distribution of dehydrogenase systems in reference to the metabolic pathway and odontogenesis in rodent teeth at cellular level from a histochemical approach.

\section{Materials and Methods}

Fetal Wistar rats from 15 to 20 days old, and two to five days after birth were used. Fresh serial sections were cut out of the animal's jaw at $20 \mu$ in a $-20^{\circ} \mathrm{C}$ cryostat. The sections were dried at room temperature and immediately incubated.

The following dehydrogenases were stained in the present experiment. Succinic dehydrogenase, DPN-dependent dehydrogenase ${ }^{10,11}$ ) (lactic, malic, glutamic, $\alpha$-glycerophosphate and $\beta$-hydroxybutyric), TPN-dependent dehydrogenase $^{(0,11)}$ (isocitric, glucose-6-phosphate and aconitase ${ }^{12)}$ ). After incubation, the sections were rinsed in distilled water, fixed in $10 \%$ neutral formalin for over 10 minutes.

\section{Results}

The localization of various dehydrogenase activities with nitro BT showed a deposition of fine rich blue granules.

Succinic dehydrogenase: A high enzymatic activity was present in the basal portion of columnar ameloblasts and adjacent stratum intermedium. The enzymatic activity in differentiated cells was more intense than in undifferentiated dental epithelia (so called the cells of the cervical loop). The pulp tissue showed only a very slight staining.

Lactic dehydrogenase: A strong activity was mainly observed in odontoblast and the basal portion of ameloblasts, being almost negative in the calcifying dentin matrix. The pulp and the cervical loop were moderately reactive for lactic dehydrogenase.

Malic dehydrogenase: Odontoblasts were most intensively reactive, and ameloblasts were less reactive than odontoblasts. The zones of primary enamel formation and predentin were not stained. The dental pulp and the cervical loop were less stained than odontoblasts.

Glutamic dehydrogenase: Undifferentiated odontoblasts and ameloblasts showed a slight staining. Differentiated ameloblasts were more deeply stained than those of odontoblasts. The pulp tissue showed only a little amount of the activity.

$\alpha$-Glycerophosphate dehydrogenase: A slight activity was present only in differentiated ameloblasts and odontoblasts. The pulp, undifferentiated dental epithelium, predentin and enamel in the process of matrix fomation were unstained.

$\beta$-Hydroxybutyric dehydrogenase: A slight activity was present only in differentiated odontoblasts. The pulp, undifferentiated dental epithelium, 
predentin and enamel in the process of matrix formation were unstained.

Isocitric dehydrogenase: The basal portion of differentiated ameloblasts and odontoblasts was slightly reactive or essentially negative. In the predentin, enamel in the process of matrix formation and dental pulp were usually devoid of stainability.

Glucose-6-phosphate dehydrogenase: A high to moderate enzymatic reaction was present in odontoblasts and at the basal portion of ameloblasts, while a slight coloration developed in the dental pulp. The enzymatic activity corresponds to the degree of calcification.

Aconitase: Undifferentiated odontoblasts and ameloblasts exhibited high to moderate enzymatic activity and in completely differentiated odontoblasts and ameloblasts there was shown an extremly intensive activity. The activity in dental pulp was moderate or slight.

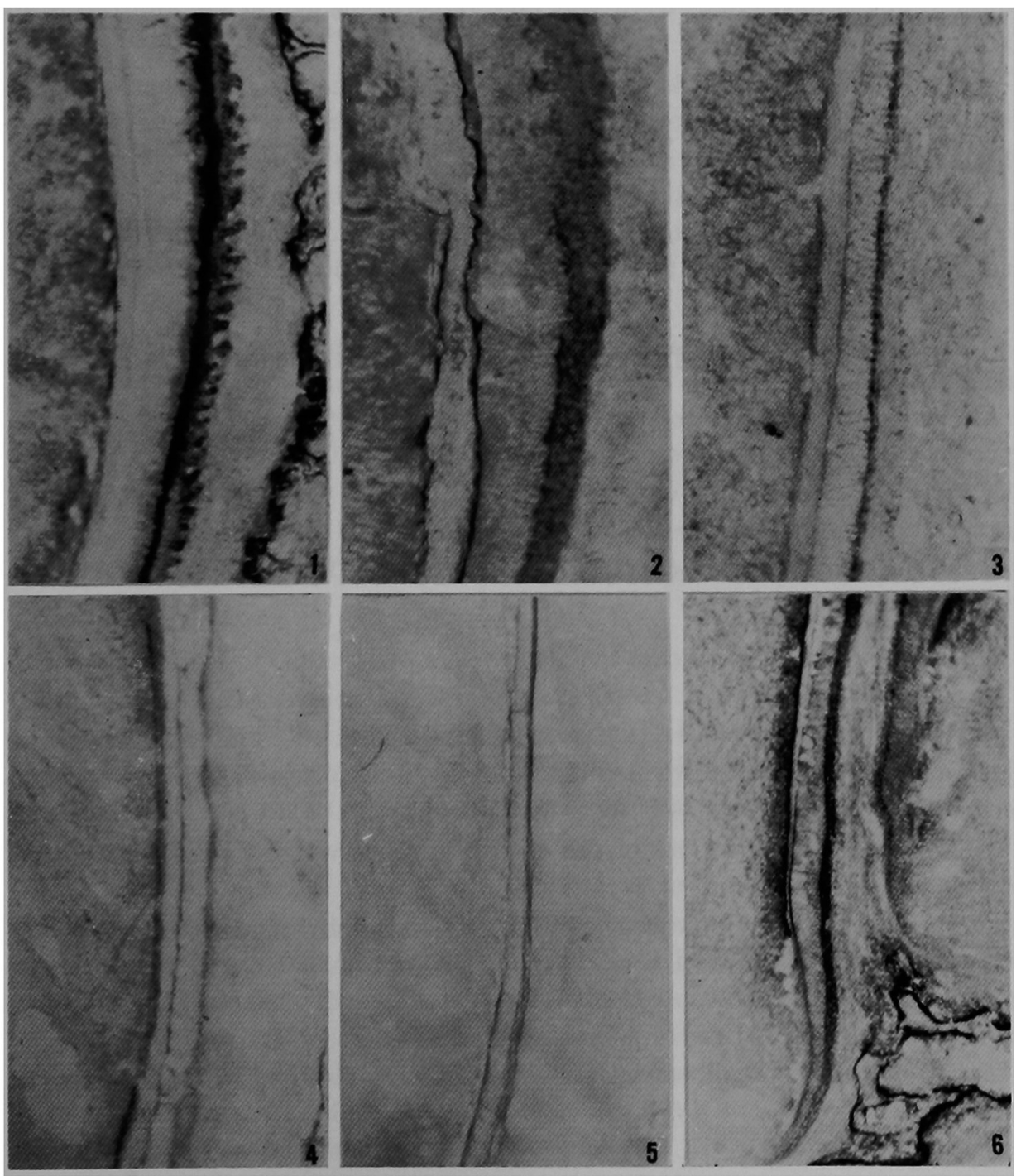




\section{Discussion}

The histochemical studies of developing teeth have been centered in the distribution of hydrolytic enzymes. The distribution of alkaline phosphatase ${ }^{2,3}$ in unerupted tooth was demonstrated only in the undifferentiated dental epithelia and the reaction was variable in ameloblasts and odontoblasts. As for the acid phosphatase reaction ${ }^{3)}$ in the developing tooth is concerned, it is reported that enzymatic activity was present in a highly calcifying zone of ameloblasts and odontoblasts, and that the activity was very low in differentiated parts. Esterase in developing teeth ${ }^{1,4,7)}$ was localized in both ameloblasts and odontoblasts, showing a similar distribution to acid phosphatase. $\beta$-Glucuronidase activity ${ }^{5,7}$ in developing teeth using the post azo coupling method was higher in matured odontoblasts and ameloblasts than that in undifferentiated cells. Aminopeptidase $^{6,7)}$ in the developing teeth was detectable in the dental sac and the basal area of the pulp.

The appearence of oxidative and reducing enzymes in a developing dental structure was rather uniform, that is, the localization of enzymes on metabolic pathways was almost the same except for the intensity of enzymatic activity. In the findings of the basal portion of mature ameloblasts, succinic dehydrogenase activity was the highest, while other DPN-dependent dehydrogenase activities were moderate to low and TPN-dependent dehydrogenase activity was low.

In general, it has been accepted that mitochondria contain oxidative and reducing enzymes. Especially the localization of succinic dehydrogenase on histochemical procedures is said to be in good accordance with the presence of mitochondria on an electronmicroscopic basis. ${ }^{13)}$ The members of TCA cycle enzymes, being with a similar distribution, showed a variable staining rate. It was suggested by the present findings that the difference in activity among the same pathway enzymes was due to the difference in their metabolic rates.

\section{Summary}

Histochemical demonstration of succinic, malic, lactic, glutamic, $\alpha$-glycerophosphate, $\beta$-hydroxybutyric, isocitric, glucose-6-phosphate dehydrogenases and aconitase in developing teeth was carried out with the nitro BT method.

The intensity of actions of the dehydrogenases was not always the same depending upon the kind of enzymes.

The enzymatic activity of succinic, malic, lactic dehydrogenase and aconitase was considerably high, while that of other DPN-dependent dehydrogenases was moderate to rather low, and TPN-dependent dehydrogenases showed a low activity.

Acknowledgment : Authors wish to thank Prof. K. Kawakatsu for his variable advice and to Assist. Prof. M. Mori for his helpful suggestion in this study. 


\title{
References
}

1) Burstone, M. S. : Arch. Path., 63, 164-167, $1957 . \quad$ 2) Johnson, P. L., \& G. Bevelander, : Oral Surg. 10, 437-443, $1957 . \quad$ 3) Mori, M., W. Yoshioka, T. Mizushima, \& N. Amatsu, : Arch. hist. jap. 20, 513-522, $1960 . \quad$ 4) Yoshioka, W., M. Mori, T. Mizushima, \& T. Amatsu, : Arch. hist. jap. 20, 523-527, $1960 . \quad$ 5) Yoshioka, W., M. Mori, T. Mizushima, \& S. Deguchi, : Arch. hist. jap. 20, 529-533, 1960 6) Mori, M., W. Yoshioka, T. Mizushima, \& M. Murakami, : Arch. hist. jap. 20, 599-601, 1960.7 7) Quintarelli, G. : Arch. Ital. Biol. Orale, 2, 1-25, $1961 . \quad 8)$ Mizushima, T., M. Mori, W. Yoshioka, \& T. Tani, : Arch. hist. jap. 20,603-608, 1960. 9) Mori., T. Mizushima, \& K. Osanai, : Histochemie 2, 348-355, 1961. 10) Nachlas, M. M., D. G. Walker, \& A. M. Seligman, : J. Histochem. Cytochem. 4, 29-38, 1958. 11) Nachlas, M. M., D. G. Walker, \& A. M. Seligman, : J. Biophys, Biochem. Cytol. 4, 467-473, $1958 . \quad$ 12) Yamada, Y., T. Abe, \& N. Shimizu, : Arch. hist. jap. 23, 165-171, 1962. 13) Shiota, K. \& T. Shizuki, : J. Jap. Stom. Soc. (Abst) 10, 1961.

\section{Explanation of Figures}

Fig. 1: Succinic dehydrogenase. $\times 200$

Fig. 2: Latic dehydrogenase. $\times 200$

Fig. 3: Malic dehydrogenase. $\times 200$

Fig. 4: $\alpha$-Glycerophosphate dehydrogenase. $\times 100$

Fig. 5: $\beta$-Hydroxybutyric dehydrogenase. $\times 100$

Fig. 6: Aconitase. $\times 100$

\section{Histochemistry of Heterotopic Hard Tissue Formation}

\author{
Transplantation of Urinary Bladder Epithelium
}

\author{
Shusaku Yoshiki \\ Department of Pathology, Tokyo Dental College Tokyo, Japan
}

The present work deals with a histochemical analysis of the bone formation which is induced by implantation of the epithelium of urinary bladder. ${ }^{8-14,20)}$

The observations were primarily focused on the hyalinized tissue and what is called "abnormal bone tissue" "1) which appear during the bone induction, and some intrinsic difference in nature between the two tissues was indicated.

\section{Methods}

The animals used were guinea pigs which were from 3 to 5 months of age. They were divided into two groups, $A$ and $B$. In group $A$ the animals were anesthetized with a $1: 2: 3$ mixture of alcohol, chloroform and ether, their abdomen opened, small piece of the urinary bladder excised and autotransplanted into the abdominal subcutaneous tissue. ${ }^{14)}$ In group $\mathrm{B}, 10-20 \mathrm{mg}$. of aminoacetonitrile (AAN) was given to each animal by intramuscular injection every day from 5 days after the transplantation. ${ }^{14)}$ 